\title{
Climate Change and Groundwater: Impact, Adaptation and Sustainable
}

\author{
Manohar Lal ${ }^{1 *}$, Bhajan Lal Sau ${ }^{2}$, Jitendra Patidar ${ }^{3}$, Abhishek Patidar ${ }^{4}$ \\ ${ }^{1}$ Dept. of Agronomy, Swami Keshwanand Rajasthan Agricultural University, Bikaner, Rajasthan (344 006), India \\ ${ }^{2}$ Dept. of Geography, Mohanlal Sukhadia University, Udaipur, Rajasthan (313 001), India \\ ${ }^{3}$ Dept. of Agronomy, Jawaharlal Nehru Krishi Vishwa Vidyalaya, Jabalpur, M.P. (482 004), India \\ ${ }^{4}$ Dept. of Agronomy, Punjab Agricultural University, Ludhiana, Punjab (141 004), India
}

\section{Corresponding Author}

Manohar Lal

e-mail: manoharalal00291@gmail.com

\author{
Article History \\ Article ID: 3C0671b \\ Received in $26^{\text {th }}$ October, 2017 \\ Received in revised form $29^{\text {th }}$ April, 2018 \\ Accepted in final form $24^{\text {th }}$ May, 2018
}

\begin{abstract}
Water is indispensable for life, but its availability at a sustainable quality and quantity is threatened by many factors, in which climate plays a leading role. Groundwater is the major source of water across the world for life particularly in rural areas of arid and semi-arid regions, but there has been very little research conducted on the potential effects of climate change. Continuous groundwater depletion of the states Gujarat, Punjab, Haryana, Tamil Nadu and Rajasthan that have registered groundwater development above the national average. The most prevalent form of irrigation in India is groundwater irrigation. Already $70 \%$ of Indian crop production is dependent on groundwater irrigation. The last 100 years, the global climate has warmed by an average of $0.5^{\circ} \mathrm{C}$ due to higher concentrations of greenhouse gases in the atmosphere. Indian landmass below the Ganges plain is likely to experience a $0.5-1{ }^{\circ} \mathrm{C}$ rise in average temperatures during $2020-2029$ and it will be rise up to $3.5-4.5^{\circ} \mathrm{C}$ at the end of century. Kharif (monsoon) season crops will experience more risk of flood as well as droughts. Rabi and especially summer crops will experience enhanced ET, needing larger, more frequent irrigation because of climate change. Adaptation to climate change and improving sustainability include improved management and governance of large irrigation systems by focusing on demand management rather than supply management. Climate change have severe adverse impact on India's precipitation patterns, ecosystems, agricultural potential, forests, water resources, coastal and marine resources. Large-scale planning would be clearly required as adaptation measures for climate change impacts, if catastrophic human misery is to be avoided and need to be mitigate the impact of climate change by adopting all possible management practices and save the ground water to sustain the future life. If the above practices were not implicated it show drastic effect on climate change which lead to cause adverse condition to living and non-living beings in developing country such as India.
\end{abstract}

Keywords: Climate Change, Groundwater, Impact, India

\section{Introduction}

Water is indispensable for life, but its availability at a sustainable quality and quantity is threatened by many factors, climate plays a leading role. The Intergovernmental Panel on Climate Change (IPCC) defines climate as "the average weather in terms of the mean and its variability over a certain time-span and a certain area" and a statistically significant variation of the mean state of the climate or its variability lasting for decades or longer, is referred to as climate change. Evidence is mounting that we are in a period of climate change brought about by increasing atmospheric concentrations of greenhouse gases. Atmospheric carbon dioxide levels has continually increased since the 1950s. The continuation of this phenomenon may significantly alter global and local climate characteristics, including temperature and precipitation. Climate change can have profound effects on the hydrologic cycle through precipitation, evapotranspiration, and soil moisture with increasing temperatures. The hydrologic cycle will be intensified with more evaporation and more precipitation. However, the extra precipitation will be unequally distributed around the globe. Some parts of the world may see significant reductions in precipitation or major alterations in the timing of wet and dry seasons. Information on the local or regional impacts of climate change on hydrological processes and water resources is becoming more important (Kumar, 2012)

Over the last 100 years, the global climate has warmed by an average of $0.5^{\circ} \mathrm{C}$ due to higher concentrations of greenhouse gases in the atmosphere. This trend will continue. This means that there will be more energy available on the earth's surface, leading to an intensification of the water cycle (IPCC, 2007a). These changes will have a substantial destabilizing effect on 
the water cycle, resulting in greater variability in precipitation and stream flows, and increasing the intensity of extreme hydrological events (IUCN, 2003).

The last 20-30 years have witnessed a 'global boom' in groundwater use for irrigation in areas subject to extended dry seasons and/or regular droughts (Llamas, 2005). About 70 $\%$ of global water contributing from rivers and groundwater utilized for irrigation (IWMI, 2007). In India, for example, the groundwater-irrigated area has increased $500 \%$ since 1960 (Shah, 2009). Today irrigated agriculture is the largest abstractor and consumer of groundwater, with almost $40 \%$ of all cultivated land under irrigation being 'water well equipped' - with large groundwater-dependent agro-economies in South and East Asia. The nations with the largest groundwater-use areas are India (39 M ha) and China (19 M ha) (Kumar, 2012).

In contrast, the net area served by groundwater has been steadily rising. Small farmers looking for opportunities to intensify and diversify their agriculture need year-round irrigation on-demand with great frequency. Tanks and canal systems are unable to meet this need; but groundwater wells are. Groundwater wells are also a better insurance against a drought than tanks and canal systems. Even as groundwater irrigation helped South Asia's smallholders survive, myriad environmental impacts have followed as a result of unmanaged over-exploitation of the resource. (Shah, 2009). The rise of the booming ground water economy and decline in surface irrigation necessitates a totally new understanding of the operating system of India's water economy and how best it can mitigate as well as adapt to the hydro-climatic change.

\section{Hydro-climatic Future}

Climate change is expected to significantly alter India's hydro climatic regime over the $21^{\text {st }}$ century. It is widely agreed that the Indo Gangetic basin is likely to experience increased water availability from snow-melt up to around 2030 but face gradual reductions thereafter. Parts of the Indo Gangetic basin may also receive less rain than in the past; but the rest of India is likely to benefit from greater precipitation. According to IPCC (2001), most Indian landmass below the Ganges plain is likely to experience a $0.5-1{ }^{\circ} \mathrm{C}$ rise in average temperatures during 2020-2029 and $3.5-4.5{ }^{\circ} \mathrm{C}$ rise in 2090-2099. Many parts of peninsular India, especially the Western Ghats, are likely to experience a $5-10 \%$ increase in total precipitation (IPCC, 2001); however, this increase is likely to be accompanied by greater temporal variability. Throughout the sub-continent, it is expected that 'very wet days' are likely to contribute more and more to total precipitation, suggesting that more of India's precipitation may be received in fewer than 100 $\mathrm{h}$ of thunderstorms-and half in less than $30 \mathrm{~h}$-as has been the case during recent decades. This is likely to mean higher precipitation intensity and larger number of dry days in a year 2. Increased frequency of extremely wet rainy seasons (Gosain and Rao, 2007) is also likely to mean increased runoff. According to Milly et al. (2008), compared to 1900-1970, most of India is likely to experience 5-20\% increase in annual runoff during 2041-60. All in all, India should expect to receive more of its water through rain than through snow; get used to snow-melt occurring faster and earlier; and cope with less soil moisture in summer and higher crop evapotranspiration (ET) demand as a consequence. For Indian agriculture, hydroclimatic change will mean the following.

- Kharif (monsoon) season crops will experience heightened risk of flood as well as droughts.

- Rabi and especially summer crops will experience enhanced ET, needing larger, more frequent irrigation.

- Surface water storages-large and small-will benefit from increased run-off but will also suffer increased evaporation from large open surfaces of reservoirs and open canal networks as a result of higher mean temperature.

- Irrigating the same area through canals will necessitate larger reservoir storage; more frequent droughts will also mean greater need for multi-year reservoir storage capacity, of which India has very little as of now.

From these points of view as well as others, managing groundwater storage will acquire greater significance for India than ever before. However, besides groundwater demand, climate change is expected to impact groundwater supply too in direct and myriad ways.

\subsection{Climate change signals}

\subsubsection{Heavy precipitation events}

- Flooding

- Adverse effects on quality of surface water and groundwater due to sewer overflows

- Contamination of water supply

\subsubsection{Higher variability of precipitation, including increased} droughts

\section{- Change in run-off}

- More widespread water stress

- Increasing frequency and magnitude of drought-like situations

- Increased water pollution due to lower dissolution of sediments, nutrients, pesticides and salt

\subsubsection{Increase in air temperatures}

- Melting glaciers and snowfields in the Himalayas affecting downstream river systems

- More evapotranspiration

\subsubsection{Increase in water temperatures}

- Changes in lake and coastal ecosystems (e.g. more algae growth, coral bleaching)

- Rising sea levels caused by thermal expansion and melting of glaciers, resulting in

- Saline intrusion of coastal and island aquifers

- Reduced quality of groundwater along the coastal plains (GOI, 2009).

The intensity of floods and severity of droughts in various parts 
of India is projected to increase. Hence, some river basins might face water scarcity (GOI, 2004). The combination of population growth and climate change is predicted to reduce the availability of fresh water in India from the current 1900 to 1000 cubic meters per capita/year by 2025 (IPCC, 2007b). Furthermore, rising sea levels may lead to increased saline intrusion into coastal and island aquifers, while increased frequency and severity of floods may affect groundwater quality in alluvial aquifers (GOI, 2004). As much as $60 \%$ of the crop area in India is rain fed, with rainfall being largely confined to the southwest monsoon season from June to September (GOI, 2004). While climate models are relatively consistent in predicting temperature increase, projecting the scope of precipitation changes remains very difficult. However, an overall increase in rainfall intensity, combined with a reduction in the number of rainy days, will have great effects for the majority of the land needed for agricultural production. North Andhra Pradesh and the west coast are already witnessing an increase in monsoon rainfall $(+10 \%$ to $+12 \%$ above the 100 -year normal) and Madhya Pradesh, North East India and parts of Gujarat and Kerala are experiencing a decrease in monsoon rainfall: - $6 \%$ to - $8 \%$ below the 100 -year normal (GOI, 2004).

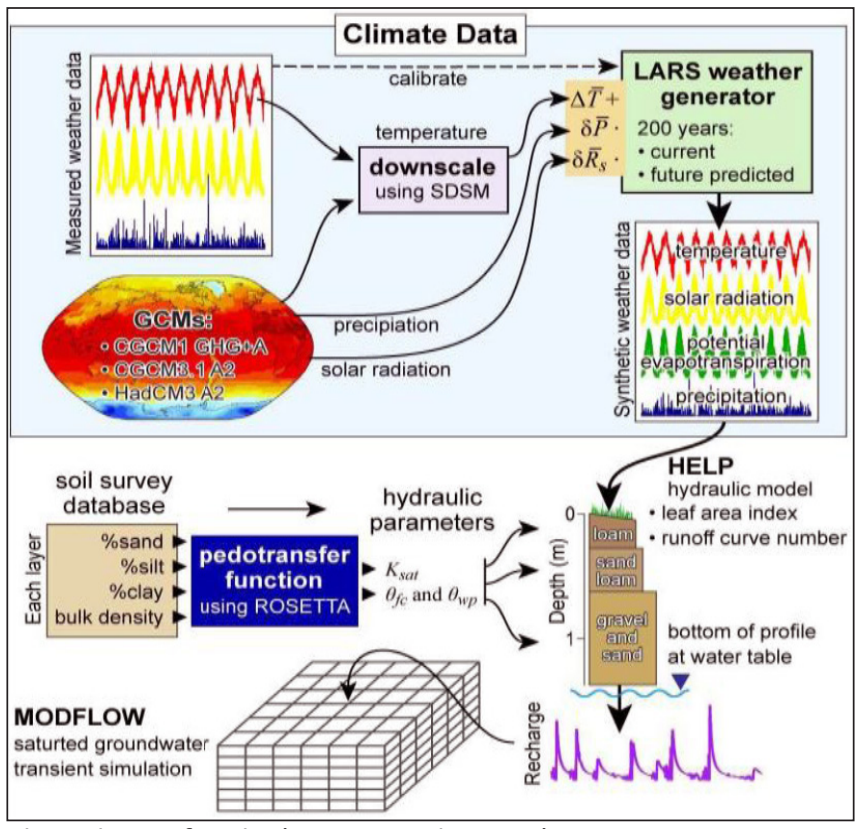

Flow chart of tasks (Toews et al., 2007)

\subsection{Climate change impacts on groundwater}

The most prevalent form of irrigation in India is groundwater irrigation. Already $70 \%$ of Indian crop production is dependent on groundwater irrigation. Expanding the irrigation potential through groundwater irrigation is often a priority based on the assumption that it not only reduces the variation in supply and is more reliable, but also provides the flexibility to cope with unforeseen water shortages. This reduces the risks for farmers in purchasing farm inputs and therefore often leads to higher agricultural productivity (Bhaduri et al., 2005). The dependence on groundwater irrigation will further increase with the impacts of climate change, especially in those areas already affected by low and irregular rainfall. Because withdrawal of groundwater often exceeds recharge, if the groundwater resource is not managed well, depletion of groundwater and degradation will pose a serious threat to farmers and the environment.

To the extent that climate change results in spatial and temporal changes in precipitation, it will significantly influence natural recharge. Moreover, since a good deal of natural recharge occurs in areas with vegetative cover, such as forests, changing ET rates resulting from rising temperatures may reduce infiltration rates from natural precipitation and thus reduce recharge. Recharge responds strongly to temporal pattern of precipitation as well as soil cover and soil properties. In the African context, Carter (2007) has argued that replacing natural vegetation by crops can increase natural recharge by up to a factor of 10 . If climate change results in changes in natural vegetation in forests or savanna, these too may influence natural recharge; however, the direction of the net effect will depend upon the pattern of changes in the vegetative cover.

Simulation models developed by Australian scientists have showed that changes in temperatures and rainfall influence growth rates and leaf size of plants that affect groundwater recharge (Kundzewicz and Doll, 2007). Changing river flows in response to changing mean precipitation and its variability, rising sea levels and changing temperatures will all influence natural recharge rates (Kundzewicz and Doll, 2007). We know little about how exactly rainfall patterns will change, but increased temporal variability seems guaranteed. This will mean intense and large rainfall events in short monsoons followed by long dry spells. All evidence we have suggests that groundwater recharge through natural infiltration occurs only beyond a threshold level of precipitation; however, it also suggests not only that runoff increases with precipitation but the run-off coefficient (i.e. run-off/precipitation) itself increases with increased rainfall intensity (or precipitation per rainfall event) (Carter, 2007). Higher variability in precipitation may thus negatively impact natural recharge in general. What will be the net impact on a given location will depend upon the change in both the total precipitation and the variability of that precipitation.

The Indo-Gangetic aquifer system has been getting heavy recharge from the Himalayan snow-melt. As snow-meltbased run-off increases during the coming decades, their contribution to potential recharge may increase; however, a great deal of this may end up as 'rejected recharge' and enhance river flows and intensify the flood proneness of eastern India and Bangladesh. As the snow-melt-based runoff begins declining, one should expect a decline in run-off as well as groundwater recharge in this vast basin.

A major interplay of climate change and groundwater will be 
witnessed in coastal areas. Using the records of coastal tide gauges in the north Indian Ocean for more than 40 years, Unnikrishnan and Shankar (2007) have estimated a sea level rise between 1.06 and $1.75 \mathrm{~mm}$ per year, consistent with the 1-2 $\mathrm{mm}$ per year global sea level rise estimates of IPCC. Rising sea levels will threaten coastal aquifers. Many of India's coastal aquifers are already experiencing salinity ingress. This problem is particularly acute in Saurashtra coast in Gujarat and Minjur aquifer in Tamil Nadu. In coastal West Bengal, Sundarbans (mangrove forest) are threatened by saline intrusion overland, affecting its aquifers. The precarious balance between freshwater aquifers and sea water will come under growing stress as sea levels rise.Some scientists suggest climate change may alter the physical characteristics of aquifers themselves. Higher $\mathrm{CO}_{2}$ concentrations in the atmosphere, they argue, may influence carbonate dissolution and promote the formation of carst which in turn may negatively affect infiltration properties of topsoils. Others have argued the opposite. From experimental data, some scientists have claimed that elevated atmospheric $\mathrm{CO}_{2}$ levels may affect plants, vadose zone and groundwater in ways that may hasten infiltration from precipitation by up to $119 \%$ in a Mediterranean climate to up to $500 \%$ in a sub-tropical climate.

\subsection{Ground water exploitation}

Continuous groundwater depletion resulting from long-term excessive resource exploitation can in some cases result in a number of other serious consequences:

- The salinisation of aquifers-which is a very insidious and often complex process arising from a variety of physical mechanisms

- Troublesome land subsidence due to the settlement of interbedded aquitards in alluvial and/or lacustrine formations increasing (and in some cases spiralling) electrical energy costs for pumping, especially where use is 'buffered' by subsidies or flat-rate tariffs-with serious implications for many electricity utilities and for the unit energy consumption and carbon footprint of irrigated agricultural production (Shah and Verma, 2008; Garduno and Foster, 2010).

The major cost component of groundwater production (once waterwells are constructed) is the energy required to lift water, which will depend on unit energy price, water-table depth, aquifer characteristics and well efficiency (which in some hydrogeological settings can decrease dramatically with declining water-table). Rural electricity pricing could thus be a very useful tool to constrain groundwater abstraction, but paradoxically it is often used in the opposite way with major subsidies in place to decrease farming costs and reduce waterprice differentials.

\subsection{Groundwater recharge}

Groundwater is the major source of water across much of the world, particularly in rural areas in arid and semiarid regions, but there has been very little research on the potential effects of climate change. Aquifers generally are replenished by effective rainfall, rivers, and lakes. This water may reach the aquifer rapidly, through macro-pores or fissures, or more slowly by infiltrating through soils and permeable rocks overlying the aquifer. A change in the amount of effective rainfall will alter recharge, but so will a change in the duration of the recharge season. Increased winter rainfall, as projected under most scenarios for midlatitudes, generally is likely to result in increased ground water recharge. However, higher evaporation may mean that soil deficits persist for longer and commence earlier, offsetting an increase in total effective rainfall. Various types of aquifer will be recharged differently. The main types are unconfined and confined aquifers. An unconfined aquifer is recharged directly by local rainfall, rivers, and lakes, and the rate of recharge will be influenced by the permeability of overlying rocks and soils. Macro-pore and fissure recharge is most common in porous and aggregated forest soils and less common in poorly structured soils. It also occurs where the underlying geology is highly fractured or is characterized by numerous sinkholes. Such recharge can be very important in some semi-arid areas. In principle, "rapid" recharge can occur whenever it rains, so where recharge is dominated by this process it will be affected more by changes in rainfall amount than by the seasonal cycle of soil moisture variability.

Shallow unconfined aquifers along floodplains, which are most common in semi-arid and arid environments, are recharged by seasonal stream flows and can be depleted directly by evaporation. Changes in recharge therefore will be determined by changes in the duration of flow of these streams, which may locally increase or decrease, and the permeability of the overlying beds, but increased evaporative demands would tend to lead to lower groundwater storage. The thick layer of sands substantially reduces the impact of evaporation. It will be noted from the foregoing that unconfined aquifers are sensitive to local climate change, abstraction, and seawater intrusion. However, quantification of recharge is complicated by the characteristics of the aquifers themselves as well as overlying rocks and soils. A confined aquifer, on the other hand, is characterized by an overlying bed that is impermeable, and local rainfall does not influence the aquifer. It is normally recharged from lakes, rivers, and rainfall that may occur at distances ranging from a few kilometers to thousands of kilometers. Aside from the influence of climate, recharge to aquifers is very much dependent on the characteristics of the aquifer media and the properties of the overlying soils. Several approaches can be used to estimate recharge based on surface water, unsaturated zone and groundwater data. Among these approaches, numerical modelling is the only tool that can predict recharge. Modelling is also extremely useful for identifying the relative importance of different controls on recharge, provided that the model realistically accounts for all the processes involved. However, the accuracy of recharge estimates depends largely on the availability of high quality hydrogeologic and climatic data. Determining 
the potential impact of climate change on groundwater resources, in particular, is difficult due to the complexity of the recharge process, and the variation of recharge within and between different climatic zones. Attempts have been made to calculate the rate of recharge by using carbon-14 isotopes and other modeling techniques. This has been possible for aquifers that are recharged from short distances and after short durations. However, recharge that takes place from long distances and after decades or centuries has been problematic to calculate with accuracy, making estimation of the impacts of climate change difficult. The medium through which recharge takes place often is poorly known and very heterogeneous, again challenging recharge modeling. In general, there is a need to intensify research on modeling techniques, aquifer characteristics, recharge rates, and seawater intrusion, as well as monitoring of groundwater abstractions. This research will provide a sound basis for assessment of the impacts of climate change and sea-level rise on recharge and groundwater resources. Rosenberg et al. (1999) studied the impact of climate change on the water yield and groundwater recharge of the Ogallala aquifer in the central United States. Three different GCMs were used to predict changes in the future climate due to anticipated changes in temperature and $\mathrm{CO}_{2}$ concentrations. The study found that recharge was reduced under all scenarios, ranging up to $7 \%$, depending on the simulation conditions. Croley and Luukkonen (2003) investigated the impact of climate change on groundwater levels in Lansing, Michigan. The groundwater recharge rates were based on an empirical stream flow model which was calibrated using the results from two GCMs. The results of the study indicated that the simulated steady-state groundwater levels were generally predicted to increase or decrease due to climate change, depending on the GCM used.

\subsection{Climate change scenario for groundwater in India}

Impact of climate change on the ground water regime is expected to be severe. It is to be pointed out that groundwater is the principle source of drinking water in the rural areas. About $85 \%$ of the rural water supply in India is dependent on groundwater. India on the whole has a potential of 45.22 $\mathrm{M}$ ha $\mathrm{m}$ year $^{-1}$ of replenishable groundwater. Unfortunately, due to rampant drawing of the subsurface water, the water table in many regions of the country has dropped significantly in the recent years resulting in threat to groundwater sustainability. These regions mainly correspond to the states of Gujarat, Punjab, Haryana, Tamil Nadu and Rajasthan that have registered groundwater development above the national average. The situation in Gujarat, in particular, is critical. The water table in Ahmedabad is reported to be going down at the rate of 4 to 5 meters every year. In some localities of Delhi, the water table has fallen by over 10 meters. Even in Kerala, where the intensity of monsoon rain is heavy, water table has been falling systematically in all parts of the State. The most optimistic assumption suggests that an average drop in groundwater level by one meter would increase India's total carbon emissions by over $1 \%$, because the time of withdrawal of the same amount of water will increase fuel consumption. A more realistic assumption reflecting the area projected to be irrigated by groundwater, suggests that the increase in carbon emission could be $4.8 \%$ for each meter drop in groundwater levels (Mall et al., 2006).

Climate change is likely to affect ground water due to changes in precipitation and evapotranspiration. Rising sea levels may lead to increased saline intrusion into coastal and island aquifers, while increased frequency and severity of floods may affect groundwater quality in alluvial aquifers. Sea-level rise leads to intrusion of saline water into the fresh groundwater in coastal aquifers and thus adversely affects groundwater resources. For two small and flat coral islands at the coast of India, the thickness of freshwater lens was computed to decrease from $25 \mathrm{~m}$ to $10 \mathrm{~m}$ and from $36 \mathrm{~m}$ to $28 \mathrm{~m}$, respectively, for a sea level rise of only $0.1 \mathrm{~m}$ (Mall et al., 2006). Increased amount of precipitation in short heavy spells will lead to low infiltration thereby causing low moisture availability for soil. Furthermore, water management systems in the area like number of reservoirs, boreholes etc. would also modify the water availability. Global warming will also affect the water supply by changes in evaporation and ground water recharge. Finally through sea level rise, the global warming may contribute saline intrusion Agricultural demand, particularly for irrigation water, which is a major share of total water demand of the country, is considered more sensitive to climate change. A change in field-level climate may alter the need and timing of irrigation. Increased dryness may lead to increased demand, but demand could be reduced if soil moisture content rises at critical times of the year. It is projected that most irrigated areas in India would require more water around 2025 and global net irrigation requirements would increase relative to the situation without climate change by $3.5-5 \%$ by 2025 and $6-8 \%$ by 2075 . In India, roughly $52 \%$ of irrigation consumption across the country is extracted from groundwater; therefore, it can be an alarming situation with decline in groundwater and increase in irrigation requirements due to climate change. Warm air holds more moisture and increase evaporation of surface moisture. With more moisture in the atmosphere, rainfall and snowfall events tend to be more intense, increasing the potential for floods. However, if there is little or no moisture in the soil to evaporate, the incident solar radiation goes into raising the temperature, which could contribute to longer and more severe droughts. Therefore, change in climate will affect the soil moisture, groundwater recharge and frequency of flood or drought episodes and finally groundwater level in different areas. In a number of studies, it is projected that increasing temperature and decline in rainfall may reduce net recharge and affect groundwater levels. However, little work has been done on hydrological impacts of possible climate change for Indian regions/basins. Existing economic growth scenarios project total power generation capacity in 
India to increase nine times from $96 \mathrm{GW}$ to $912 \mathrm{GW}$ between 1995-2100. As a result of climate change, it is estimated that approximately $1.5 \%$ more power generation capacity will be required. Increased energy demand may arise from a number of sources. For example, increases in average temperature can result in the need for space cooling for buildings, and variability in precipitation can impact irrigation needs and consequent demand for energy from groundwater pumping (Kumar, 2012).

\subsection{Adaptation to climate change and improving sustainability}

Options for adaptation to climate change and improving sustainability include improved management and governance of large irrigation systems by focusing on demand management rather than supply management. This includes improving water use efficiency and helping to reduce water losses. In addition, alternatives to groundwater irrigation, such as water harvesting and the use of marginal water (See below), must be provided. The easy access to and availability of water for irrigation often leads to higher consumption levels than actually needed by farmers. The inefficiency and lack of water pricing structures that reflect the actual price of water hardly provides any incentive for farmers to conserve their water resources. Improved water use efficiency can be achieved by:

- Technical modernization of the design and operation of new or rehabilitated irrigation systems;

- improved on-farm water management, including watersaving technology (especially drip irrigation);

- Volumetric water prices as an incentive to save water;

- Cropping patterns, plant breeding and crop-growing practices that are suited to water availability and soil conditions;

- Agricultural research that focuses on water saving, e.g. in connection with traditional crops, improved crop-growing practices and increased use of salt-tolerant plants. (GTZ, 2008, GOI, 2009; World Bank, 2010).

Mall et al. (2006) examined the potential for sustainable development of surface water and groundwater resources within the constraints imposed by climate change and future research needs in India. In recent times, several studies around the globe show that climatic change is likely to impact significantly upon freshwater resources availability. In India, demand for water has already increased manifold over the years due to urbanization, agriculture expansion, increasing population, rapid industrialization and economic development. At present, changes in cropping pattern and land-use pattern, over-exploitation of water storage and changes in irrigation and drainage are modifying the hydrological cycle in many climate regions and river basins of India. An assessment of the availability of water resources in the context of future national requirements and expected impacts of climate change and its variability is critical for relevant national and regional long-term development strategies and sustainable development. He concluded that the Indian region is highly sensitive to climate change. The elements/sectors currently at risk are likely to be highly vulnerable to climate change and variability. It is urgently required to intensify in-depth research work with the following objectives:

- Analyze recent experiences in climate variability and extreme events, and their impacts on regional water resources and groundwater availability.

- Study on changing patterns of rainfall, i.e. spatial and temporal variation and its impact on run-off and aquifer recharge pattern.

- Study sea-level rise due to increased run-off as projected due to glacial recession and increased rainfall.

- Sea-water intrusions into costal aquifers.

- Determine vulnerability of regional water resources to climate change and identify key risks and prioritize adaptation responses.

- Evaluate the efficacy of various adaptation strategies or coping mechanisms that may reduce vulnerability of the regional water resources.

It has been the endeavor of this study to summarize some important vulnerability issues associated with the present and potential future hydrological responses due to climate change and highlight those areas where further research is required. The National Environment Policy (2004) also advocated that anthropogenic climate changes have severe adverse impacts on India's precipitation patterns, ecosystems, agricultural potential, forests, water resources, coastal and marine resources. Large-scale planning would be clearly required for adaptation measures for climate change impacts, if catastrophic human misery is to be avoided.

Shah (2009) reviewed the India's climate change and groundwater. For millennia, India used surface storage and gravity flow to water crops. During the last 40 years, however, India has witnessed a decline in gravity-flow irrigation and the rise of a booming "water-scavenging irrigation economy through millions of small, private tube wells. For India, groundwater has become at once critical and threatened. Climate change will act as a force multiplier; it will enhance ground water's criticality for drought-proofing agriculture and simultaneously multiply the threat to the resource. Groundwater pumping with electricity and diesel also accounts for an estimated 16-25 million mt of carbon emissions, 4-6\% of India's total. From a climate change point of view, India's groundwater hotspots are western and peninsular India. These are critical for climate change mitigation as well as adaptation. To achieve both, India needs to make a transition from surface storage to "managed aquifer storage" as the center pin of its water strategy with proactive demand-and supply-side management components. In doing this, India needs to learn intelligently from the experience of countries like Australia and the United States that have long experience in managed aquifer recharge.

Comprehensive management approaches to water resources 
that integrate ground water and surface water may greatly reduce human vulnerability to climate extremes and change, and promote global water and food security. Conjunctive uses of ground water and surface water that use surface water for irrigation and water supply during wet periods, and ground water during drought, are likely to prove essential (Faunt, 2009). Recognition of current uncertainty in water resource projections and the longer residence time (decadal to multigenerational) of fresh water in groundwater systems will be critical in setting sustainability goals (Gleeson, 2012). Managed aquifer recharge wherein excess surface water, desalinated water and treated waste water are stored in depleted aquifers could also supplement groundwater storage for use during droughts (Faunt, 2009; Sukhija, 2008). Indeed, the use of aquifers as natural storage reservoirs avoids many of the problems of evaporative losses and ecosystem impacts associated with large, constructed surface-water reservoirs. In South Asia, for example, intensive groundwater abstraction for dry-season irrigation has induced greater recharge in areas with permeable soils by increasing available groundwater storage during the subsequent monsoon (Shamsudduha et al., 2011). In northern Europe, capture of projected increases in groundwater recharge during winter may help to sustain anticipated increases in summer demand (Hiscock et al, 2011). Explicit representation in GCMs of groundwater storage, its interactions with surface-water stores, and anthropogenic perturbations-such as large-scale groundwater-fed irrigationis required to advance our understanding of both the influence of ground water on climate and the impact of climate change on global freshwater resources.

A fundamental impediment to using the adaptation strategies discussed earlier is the lack of groundwater observations to inform them. Since 2002, GRACE satellite observations have provided valuable information on recent groundwater storage changes at basin scales, but ground-based data are essential to constrain satellite observations and to inform local groundwater responses to climate and abstraction. The Global Groundwater Monitoring Network (GGMN), initiated in 2007 by the UNESCO International Hydrological Programme (IHP) International Groundwater Resources Assessment Centre to facilitate the sharing of groundwater information globally, has begun collating data sets from publicly accessible sources and via participatory processes. An expansion of groundwater monitoring, together with increased contributions of data to the GGMN, are necessary to improve access to groundwater data globally and promote the inclusion of ground water in the assessment and management of freshwater resources under climate change (Mac Donald, 2012).

\section{Conclusion}

Climate change has been widely recognized, research on the impacts of climate change on the groundwater system is relatively limited. The reasons may be that long historical data are required to analyze the characteristics of climate change.
These data are not always available. Also, the driving forces that cause such changes are yet unclear. The relationship between climate change and loss of fresh groundwater resources is important for understanding the characteristics of the different regions. The impact of future climatic change may be felt more severely in developing countries such as India.

\section{Acknowledgement}

The first author is thankful to the anonymous reviewer/ referee for the valuable research paper on climate change and groundwater to improve the paper. Author is also thankful to the co-author for suitable support.

\section{References}

Bhaduri, A., Amarasinghe, U., Shah, T., 2005. An Analysis of Groundwater Irrigation Expansion in India, 61-64.

Carter, R.C., 2007. Climate, population and groundwater in Africa Int. Conf. Groundwater and Climate in Africa (Kampala, June 2008), 81.

Croley, T.E., Luukkonen, C.L., 2003. Potential effects of climate change on ground water in Lansing, Michigan, Journal of the American Water Resources Association 39(1), 149-163.

Faunt, C.C., 2009. Groundwater Availability of the Central Valley Aquifer, California (US Geological Survey).

Garduno, H., Foster, S., 2010. Sustainable groundwater irrigation-approaches to reconciling demand with resources. World Bank/GWP GW-MATE Strategic Overview Series SO-4. 78. (Washington DC, USA).

Gleeson, T., 2012. Towards sustainable groundwater use: Setting long-term goals, backcasting, and managing adaptively. Ground Water 50, 19-26.

Gol-Government of India, Ministry of Environment and Forest, 2004. India's National Communication to the UNFCCC. 37.

Gol-Government of India, Ministry of Water Resources, 2009. National Water Mission under National Action Plan on Climate Change, 48-51.

Gosain, A.K., Rao, S., 2007. Impact assessment of climate change on water resources of two river systems in India Jalvigyan Sameeksha, 22-21.

GTZ, 2008: Sustainable Sanitation in India. Examples from Indo-German Development Cooperation, 42-44.

Hiscock, K., Sparkes, R., Hodgson, A., 2011. in Climate Change Effects of Groundwater Resources: A Global Synthesis of Findings and Recommendations. Treidel, H., MartinBordes, J.L., Gurdak, J.J. (Eds), 351-365.

Intergovernmental Panel on Climate Change, 2001. Climate change: impacts, adaptation and vulnerability Third Assessment Report of Intergovernmental Panel on Climate Change (Cambridge: Cambridge University Press). 22.

IPCC-Intergovernmental Panel on Climate Change, 2007a. 
Summary for Policymakers. In: Solomon, S., Qin, D., Manning, M., Chen, Z., Marquis, M., Averyt, K.B., Tignor, M., Miller, H.L., 2007. Climate Change 2007. The Physical Science Basis. Contribution of Working Group I to the Fourth Assessment Report of the Intergovernmental Panel on Climate Change, 58.

IPCC-Intergovernmental Panel on Climate Change, 2007b. Freshwater resources and their management. In: Parry, M.L., Canziani, O.F., Palutikof, J.P., van der Linden, P.J., Hanson, C.E., 2007. Climate Change 2007. Impacts, Adaptation and Vulnerability. Contribution of Working Group II to the Second Assessment Report of the Intergovernmental Panel on Climate Change. 34.

IUCN-International Union for Conversation of Nature 2003. Change - Adaptation of water resources management to climate change, 18.

IWMI-International Water Management Institute 2007. Comprehensive Assessment of Water Management in Agriculture, 41.

Kumar, C.P., 2012. Climate Change and Its Impact on Groundwater Resources. International Journal of Engineering and Science 1(5), 43-60

Kundzewicz, Z.W., Doll, P., 2007. Will groundwater ease freshwater stress under climate change? Int. Conf. Groundwater and Climate in Africa (Kampala, June 2008), 321-324.

Llamas, M.R., Martinez-Santos, P., 2005. Intensive groundwater use: silent revolution and potential source of social conflicts. ASCE Journal Water Resources Planning \& Management 131, 337-341.

MacDonald, A., 2012. Quantitative maps of groundwater resources in Africa. Environ. Res. Lett. 7, 024009.

Mall, R.K., Gupta, A., Singh, R., Singh, R.S., Rathore, L. S., 2006. Water resources and climate change: An Indian perspective, Current Science 90(12), 1610-1626.

Milly, P.C.D., Betancourt, J., Falkenmark, M., Hirsch, R.M., Kundzewicz, Z.W., Lettenmaier, D.P., Stouffer, R.J.,
2008. Stationarity is dead: wither water management? Science 319, 573-4

Rosenberg, N.J., Epstein, D.J., Wang, D., Vail, L., Srinivasan, R., Arnold, J.G., 1999. Possible impacts of global warming on the hydrology of the Ogallala Aquifer Region, Climatic Change 42, 677-692.

Scanlon, B.R., 2012. Groundwater depletion and sustainability of irrigation in the US High Plains and Central Valley. Proceedings of the National Academy of Sciences USA 109, 9320-9325.

Shah, T., Verma, S., 2008. Co-management of electricity and groundwater: an assessment of Gujurat's Jyoti-Gram Scheme. Indian Economic \& Political Weekly 43 7, 59-66.

Shah, T., 2009. Climate change and groundwater: India's opportunities for mitigation and adaptation, Environmental Research Letter 4, 13, IOP Publishing Ltd, UK.

Shamsudduha, M., Taylor, R.G., Ahmed, K.M., Zahid, A., 2011. The impact of intensive groundwater abstraction on recharge to a shallow regional aquifer system: Evidence from Bangladesh. Hydrogeology Journal 19, 901-916.

Sukhija, B.S., 2008. Adaptation to climate change: Strategies for sustaining groundwater resources during droughts. Geological Society Spl 288, 169-181.

Toews Michael, W., 2007. Modelling climate change impacts on groundwater recharge an a semi-arid region, southern okanagan, British Columbia, A thesis submitted in partial fulfillment of the requirements for the degree of Master of Science in the Department of Earth Sciences, Simon Fraser University, 72.

Unnikrishnan, A.S., Shankar, D., 2007. Are sea levels trends along the North Indian ocean coasts consistent with global estimates? Glob. Planet. Change 57, 301.

World Bank, 2010. Unleashing the Potential of Renewable Energy in India. South Asia Energy Unit, Sustainable Development Department, 14. 